\title{
Distal radius fractures: current concepts
}

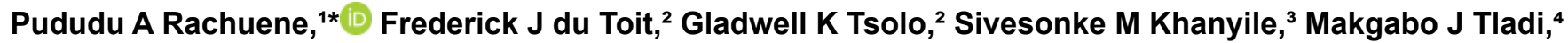 \\ Sikheto S Golele ${ }^{5}$
}

\author{
${ }_{1}$ Department of Orthopaedics, Shoulder and Elbow Unit, Sefako Makgatho Health Sciences University, Dr George Mukhari Academic Hospital, \\ Pretoria, South Africa \\ ${ }^{2}$ Department of Orthopaedics, Sefako Makgatho Health Sciences University, Dr George Mukhari Academic Hospital, Pretoria, South Africa \\ ${ }^{3}$ Department of Orthopaedics, Female Trauma Unit, Sefako Makgatho Health Sciences University, Dr George Mukhari Academic Hospital, Pretoria, \\ South Africa \\ ${ }^{4}$ Louis Pasteur Private Hospital, Pretoria, South Africa \\ ${ }^{5}$ Department of Orthopaedics, Department of Hands and Microsurgery, Sefako Makgatho Health Sciences University, Dr George Mukhari Academic \\ Hospital, Pretoria, South Africa
}

${ }^{*}$ Corresponding author: archie.pududu@gmail.co.za

Citation: Rachuene PA, Du Toit FJ, Tsolo GK, Khanyile SM, Tladi MJ, Golele SS. Distal radius fractures: current concepts. SA Orthop J 2021;20(4):231-239. http://dx.doi. org/10.17159/2309-8309/2021/ v20n4a7

Editor: Prof. Leonard C Marais, University of KwaZulu-Natal, Durban, South Africa

Received: February 2021

Accepted: May 2021

Published: November 2021

Copyright: ( 2021 Rachuene PA. This is an open-access article distributed under the terms of the Creative Commons Attribution Licence, which permits unrestricted use, distribution and reproduction in any medium, provided the original author and source are credited.

Funding: No funding was received for this study.

Conflict of interest: The authors declare they have no conflicts of interest that are directly or indirectly related to the research.

\begin{abstract}
Distal radius fractures (DRFs) are commonly encountered in the elderly population, secondary to low-energy injury mechanisms. In the younger population, DRFs are mainly secondary to highenergy trauma. Stable DRFs can be treated conservatively. However, in the elderly population group, DRFs are often unstable and are likely to benefit from surgical intervention. They are often compounded by comorbid medical conditions requiring optimisation. When treating the elderly group, one should be aware of sarcopaenia, as this may have a bearing on return to function. Recent literature reports an increasing trend in the surgical management of these fractures. Current classification systems fail to consistently guide the management of these fractures. Although evidence is still limited in guiding decision-making in the treatment of these fractures, one should consider the economic implications of prolonged immobilisation in young patients in addition to defined indications for surgery. Improvement in implants allows safe dorsal fixation in patients with dorsal comminution, with low complication rates reported. This narrative review summarises current trends and the body of evidence.
\end{abstract}

Level of evidence: Level 5

Keywords: distal radius, fracture management, osteoporosis

\section{Introduction}

Having noted a trend of steady increase in life expectancy globally, the World Health Organization (WHO) declared the years 2020 to 2030 as a decade of healthy ageing. The main aim of this declaration is to develop and maintain the functional ability that enables the wellbeing of the elderly population. Most people over the age of 60 years live in low- to middle-income countries. ${ }^{1}$ In South Africa, as of mid-2020, the estimated life expectancy was 68.5 and 62.5 years for females and males respectively, showing a steady annual increase. ${ }^{2}$ Distal radius fractures (DRFs) are the second most common fragility fracture. ${ }^{3}$ About $1.5 \%$ of the patients treated in the emergency unit will present with DRFs, of which $5-17 \%$ are due to low-energy injury mechanisms in osteoporotic patients. ${ }^{4-6}$ In an epidemiological review of the Swedish registry,
Rundgren et al. noted a higher prevalence of DRFs in females over the age of 50 years compared to males of the same age. ${ }^{7}$ The incidence of DRFs in young adults is low, and usually follows high-energy trauma or sports-related injuries, often presenting with complex fracture patterns..$^{8-10}$

\section{Economic burden}

More reconstruction options are available for the treatment of these injuries, each with cost implications. A recent review of a commercial claims database in the United States found conservative management to remain the treatment of choice throughout various demographic groups. ${ }^{11}$ More recent literature reported a shift towards surgical intervention in these fractures. ${ }^{12}$ 

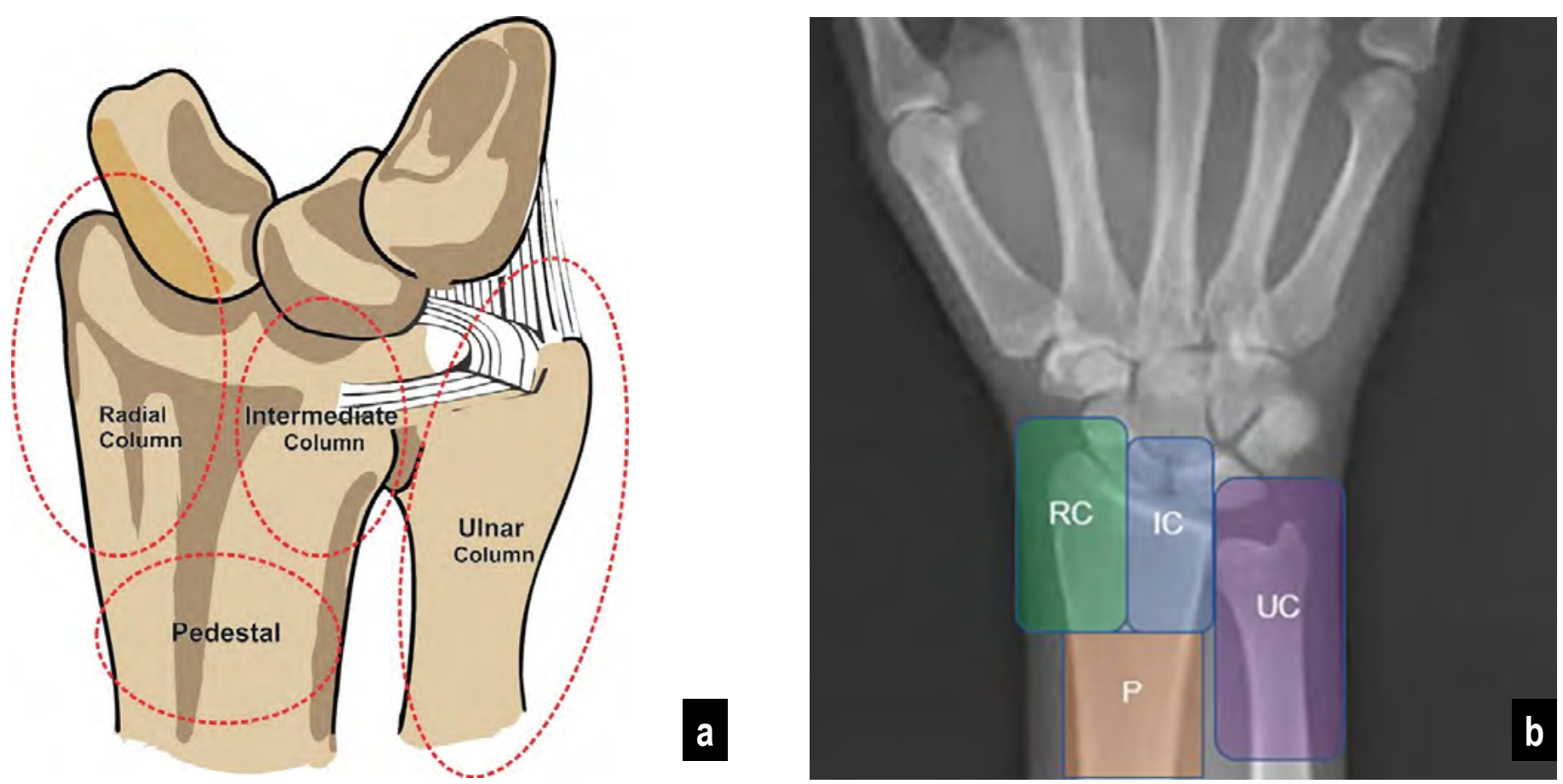

Figure 1. An image and posteroanterior view plain X-ray representing the columns of the distal radius (RC: radial column, IC: intermediate column, UC: ulnar column, $P$ : pedestal)

(Adapted from: Rhee PC, Medoff R, Shin AY. Complex distal radius fractures: An anatomic algorithm for surgical management. J Am Acad Orthop Surg. 2017;25(2):77-88. https://doi.org/10.5435/JAAOS-D-15-00525)

Mauck and Swigler reported an incidence of 634000 DRFs annually in the American elderly population, with a high financial burden ranging from 385 to 535 million US dollars annually. ${ }^{4}$ Comparing treatment options for DRFs in adults from the Medicare dataset, Shauver et al. found the cost of surgery to be almost twice the cost of closed reduction and casting. Among young adults, an additional financial burden applies in the form of 'loss of productivity' due to the inability to perform their employment responsibilities. ${ }^{13}$

\section{Historical background}

Abraham Colles noted the deformities in patients he treated for DRFs in 1814, decades before X-rays were available. He reported good functional outcomes following closed reduction and a splintage with a 'narrow wooden-splint'. ${ }^{14}$ With the advancement in radiological investigations, fixation methods and arthroscopic skills, the understanding and management of these injuries is evolving from mostly conservative treatment methods to advanced fracture fixation methods, arthroscopic-assisted surgery and arthroplasty procedures. ${ }^{15,16}$

\section{Anatomic considerations}

The distal radius is functionally made up of three columns formed by osteo-ligamentous structures; it rests on a pedestal and transmits $80 \%$ of the axial load through the wrist (Figure 1). ${ }^{17}$

\section{The radial column}

The radial column consists of the radial styloid and the scaphoid fossa, the insertion of the brachioradialis tendon, the long radiolunate ligament and radio-scapho-capitate ligament. This column serves as a radial buttress for the carpal bones during wrist ulnar deviation and weight bearing. ${ }^{4,18}$ This column is often spared in patients with injuries secondary to axial forces. The brachioradialis is responsible for radial deviation, tilt and loss of radial height in these fractures. ${ }^{18}$

\section{Intermediate column}

The intermediate column is made up of the lunate facet and sigmoid notch and serves as the load transmission column. ${ }^{18}$ The ligamentous structures are the short radiolunate and volar distal radioulnar ligaments attached to the volar rim fragment; the dorsal radiocarpal ligament attached on the dorsal wall; and the dorsal distal radioulnar ligament attached to the dorsal ulnar corner. Fractures of the dorsal wall, volar rims, intra-articular fragments and dorsal ulnar corner form part of the intermediate column fractures. ${ }^{17}$ The dorsal wall provides functional stability against dorsal carpal subluxation. Shear force, axial loads and bending mechanisms can result in fractures of this dorsal wall. ${ }^{18}$ Fractures of the ulnar corner and more than $10 \mathrm{~mm}$ radial height loss are associated with unstable distal radioulnar joint (DRUJ) and triangular fibrocartilaginous complex (TFCC) injuries. ${ }^{19,20}$

Reduction of the articular fragment is important for the restoration of the lunate facet. The lunate-lunate facet ratio (LLFR), measured on the lateral view, can help to determine the degree of articular separation. ${ }^{4}$ Articular surface congruency is best assessed with Medoff's teardrop angle (TDA), formed by a line through the central axis of the teardrop and a line in the centre of the distal radius where normal is $68^{\circ}$ on the lateral view plain X-rays. ${ }^{21}$

\section{The pedestal}

The pedestal is the metadiaphyseal segment, immediately proximal to the radial and intermediate columns. Fractures extending into the pedestal are seen in high-energy injuries. ${ }^{4,17}$

\section{Evaluation}

\section{Clinical evaluation}

Clinical examination should include a neurovascular assessment. Careful assessment of the median nerve is important, especially if there is a complaint of paraesthesia or numbness. This may indicate acute carpal tunnel syndrome (CTS). Acute CTS has 
been reported in $5.4-8.6 \%$ of patients with DRFs. It may develop rapidly, and the diagnosis is made by establishing the presence of severe paraesthesia in the median nerve distribution and sensory testing with two-point discrimination testing and SemmesWeinstein monofilament testing. ${ }^{22,23}$ Skin puncture is common in elderly patients with thin soft tissues. Care must be taken to avoid shearing of these tissues, especially during closed reductions. ${ }^{24}$

Evaluation of elderly patients with DRFs should include assessment of the muscle mass. The Asian Working Group for Sarcopenia recommends the evaluation of hand grip strength and gait speed to diagnose sarcopaenia. ${ }^{25}$ The presence of sarcopaenia has been reported to be prevalent in elderly patients with DRFs and it is closely associated with osteoporosis. Roh et al. reported $34 \%$ of men and $27 \%$ of women over the age of 50 years had sarcopaenia in a review of 264 patients with DRFs. ${ }^{26}$ The presence of sarcopaenia is associated with poor functional recovery after DRF surgery. ${ }^{27}$

\section{Radiographic evaluation}

A minimum of posteroanterior (PA) and lateral view plain X-rays is mandatory for the initial fracture evaluation. ${ }^{4}$ An additional $45^{\circ}$ pronated oblique view can be added if deemed necessary. This view is helpful with profiling the dorsal ulnar cortex and lends insight into this biomechanically important region. ${ }^{9}$

\section{Computed tomography scan}

Coronal and axial computed tomography (CT) images with $2 \mathrm{~mm}$ slices provide a detailed view for fracture configuration, in occult or complex fractures as well as an assessment of the reduction..$^{28}$ In a study on the utility of radiographs, two-dimensional (2D) CT scans and three-dimensional (3D) CT scans on 30 DRFs, Harness et al. found $3 D$ CT scans to be highly reliable and accurate over other studies and influenced treatment recommendations. ${ }^{29}$ A CT scan should be considered in patients undergoing open reduction and internal fixation (ORIF) or when information about comminution and joint depression is needed. ${ }^{30}$

\section{Classifications}

Most DRF classification systems are descriptive in nature and fail to guide on management. The McMurty and Jupiter as well as the Frykman, Melone and Mayo classification systems focus on the amount of articular involvement, whereas those by Gartland and Werley, and Older and Jenkins emphasise the amount of comminution. ${ }^{31}$ The AO classification lacks interobserver reliability and is mainly used for research and documentation.,32-34 The IDEAL classification ${ }^{35}$ is a five-factor mnemonic used to classify DRFs into three broad groups which could predict stability, guide management and prognosticate. Validation and reproducibility are yet to be confirmed. No classification has been proven to be superior in terms of determining prognosis or guiding management. $4,31,35$ Table I shows a summary of the results of selected studies evaluating inter-rater reliability of the commonly used classification systems.

\section{Management of distal radius fractures}

\section{Decision-making}

The aim of treating DRFs should be to restore wrist anatomical alignment and function. Important factors to consider in decisionmaking are patient's age, hand dominance, fracture pattern and radiographic parameters. . $^{3,440,41}$ Decision on treatment should be tailored based on patient-specific factors. ${ }^{42}$

Being able to predict fracture instability and loss of reduction remains the greatest challenge to treating surgeons. A Cochrane review of 60 DRFs in elderly patients managed with closed reduction found loss of reduction to be at a rate of $88 \%$, of which $75 \%$ occurred within one week. ${ }^{33}$

In 1989, Lafontaine et al. proposed that unstable fractures are likely to occur in patients aged 60 years and above and a fracture with greater than $20^{\circ}$ dorsal angulation, dorsal comminution, associated ulnar fracture and intra-articular involvement. ${ }^{43}$ These findings have been supported by other authors. Mackenney et al. prospectively reviewed 4000 DRFs over a 5.5-year period with the aim of predicting early and late fracture instability and resultant fracture malunion. They found advanced patient age, fracture

Table I: Selected studies showing reliability of the classification systems for distal radius fractures

\begin{tabular}{|c|c|c|c|c|}
\hline Study & Participants (n) & $\begin{array}{l}\text { Image modality } \\
\text { (number of wrists) }\end{array}$ & $\begin{array}{l}\text { Inter-rater reliability on } \\
\text { radiographs } \\
\text { (kappa values) }\end{array}$ & $\begin{array}{l}\text { Interobserver reliability on } \\
\text { radiographs and CT images } \\
\text { (kappa values) }\end{array}$ \\
\hline Azi, et al. $2019^{36}$ & $\begin{array}{l}\text { Orthopaedic surgeons } \\
(n=5)\end{array}$ & $\begin{array}{l}\text { Plain radiographs and } \\
\text { CT images }(n=43)\end{array}$ & $\begin{array}{l}\text { AO/OTA } \\
\text { Mean ICC: } 0.11 \text { (poor) }\end{array}$ & Mean ICC: 0.28 (fair) \\
\hline Van Buijtenen, et al. $2015^{37}$ & $\begin{array}{l}\text { Trauma consultants (2) } \\
\text { Radiology consultant (1) } \\
\text { Trauma registrars (2) } \\
\text { Intern (1) }\end{array}$ & $\begin{array}{l}\text { Plain radiographs } \\
(\mathrm{n}=54)\end{array}$ & $\begin{array}{l}\text { AO/OTA } \\
\text { Mean ICC: } 0.49 \text { First attempt } \\
\text { and } 0.3 \text { (on second attempt) } \\
\text { (fair) }\end{array}$ & - \\
\hline Kleinlugtenbelt, et al. $2017^{38}$ & $\begin{array}{l}\text { Surgeons with over ten } \\
\text { years experience }(n=4)\end{array}$ & $\begin{array}{l}\text { Plain radiographs and } \\
\text { CT images }(n=51)\end{array}$ & $\begin{array}{l}\text { Frykman classification } \\
\text { Mean ICC: } 0.45 \text { (fair) } \\
\text { Fernandez } \\
\text { Mean ICC: } 0.38 \text { (poor) } \\
\text { Universal } \\
\text { Mean ICC: } 0.32 \text { (poor) } \\
\text { AO/OTA } \\
\text { Mean ICC: } 0.46 \text { (fair) }\end{array}$ & $\begin{array}{l}\text { Mean ICC: } 0.28 \text { (poor) } \\
\text { Mean ICC: } 0.44 \text { (fair) } \\
\text { Mean ICC: } 0.43 \text { (fair) } \\
\text { Mean ICC: } 0.40 \text { (fair) }\end{array}$ \\
\hline Mansu and Gripp $2020^{39}$ & $\begin{array}{l}\text { Registrars }(n=4) \\
\text { Consultants }(n=8)\end{array}$ & $\begin{array}{l}\text { Plain radiographs } \\
(\mathrm{n}=14)\end{array}$ & $\begin{array}{l}\text { Frykman classification } \\
\text { Mean ICC: } 0.36 \text { (poor) } \\
\text { Universal } \\
\text { Mean ICC: } 0.48 \text { (fair) } \\
\text { AO/OTA } \\
\text { Mean ICC: } 0.25 \text { (poor) }\end{array}$ & - \\
\hline
\end{tabular}


comminution and alteration in ulnar variance to be significant predictive factors of loss of reduction. ${ }^{44}$ Similarly, a more recent systematic review and meta-analysis identified dorsal fracture comminution and female patients aged over 60 years to be significant predictive factors of fracture instability. ${ }^{45}$

\section{Treatment methods}

\section{Non-surgical treatment}

Closed reduction and cast immobilisation remain an acceptable treatment modality for stable fractures with reported good results in elderly patients even in the presence of intra-articular involvement. ${ }^{46}$ There was no difference in failure rate or final position at five weeks when the fracture was treated with finger trap traction or manipulation. ${ }^{47}$ Appropriate splintage should be used. Figure 2 shows X-rays of a patient with successful closed reduction and below-elbow cast immobilisation. There is limited evidence on the usage of above-elbow immobilisation compared to below-elbow immobilisation. ${ }^{48}$

Fracture reduction quality can be assessed with X-rays in a cast. Dailey et al. found no difference between the usage of a mini $\mathrm{C}$-arm and taking radiographs in an orthosis when measuring the quality of reductions. ${ }^{49}$ There is a lack of reliable evidence for radiographic evaluation of DRFs treated with closed reduction in the literature. The American Academy of Orthopedic Surgeons (AAOS) recommends weekly X-rays for the first three weeks and subsequent $X$-rays to be taken at six weeks to monitor alignment. ${ }^{48}$ The results of closed reduction and cast immobilisation were reported to be comparable to those of patients treated surgically for displaced DRFs in a randomised controlled trial of 100 patients aged over 65 years at 12 months follow-up..$^{50}$ In the young active population, one should remember that a displacement of the fracture in a cast will delay the return to work or sporting activities.

\section{Closed reduction and percutaneous pinning}

Stable extra-articular fractures can be treated with closed reduction and percutaneous pin fixation. Several pinning techniques have been described in the literature, with the aim of achieving fracture stability and promoting early mobilisation. Most techniques recommend the use of at least three pins with minimum $40^{\circ}$ crossing angle to ensure stability. ${ }^{41,51,52}$ One should be wary of pinsite infection.

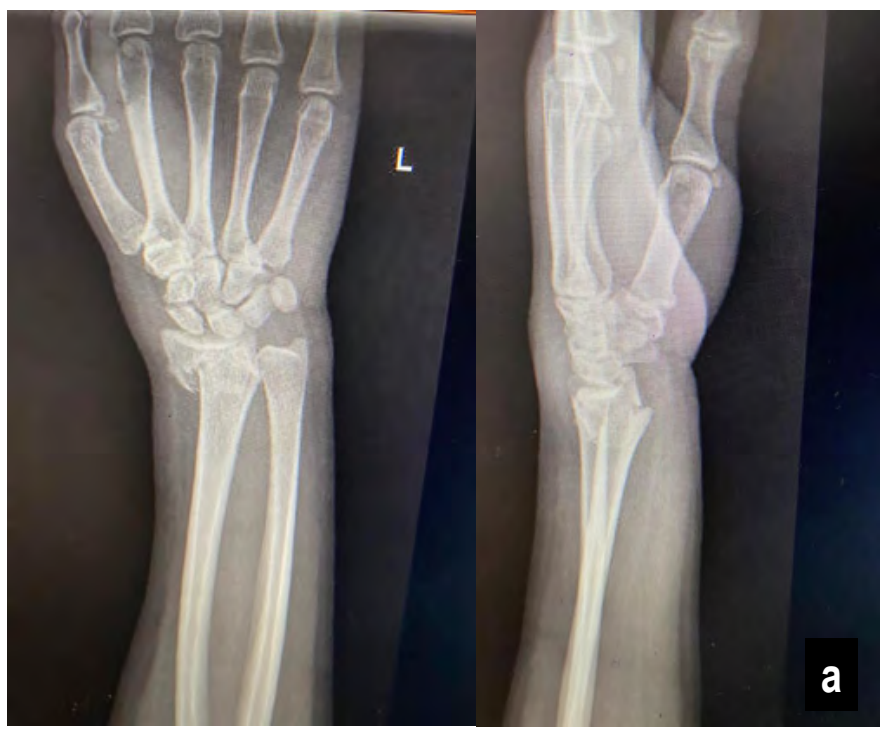

A randomised multicentre trial (DRAFFT) was done on patients ( $n=461$ adults, mean age 59.1 years) who underwent distal radius acute fracture fixation for dorsally displaced fractures within $3 \mathrm{~cm}$ of the radiocarpal joint, from 18 centres in the United Kingdom. No difference was found in functional outcomes, quality of life and number of complications between the group treated with closed reduction and percutaneous K-wire fixation $(n=230)$ compared to those treated with volar-locking plate fixation $(n=231)$ at 12 months. ${ }^{52}$ A five-year follow-up of this population revealed no difference in wrist pain, function and quality of life between the two arms of treatment. ${ }^{53}$

\section{Surgical fixation \\ Indications}

The AAOS recommend surgical fixation if post-reduction radial shortening is greater than $3 \mathrm{~mm}$, dorsal tilt is greater than $10^{\circ}$, or intra-articular displacement or step-off is greater than $2 \mathrm{~mm} .{ }^{48}$ Unstable fractures with dorsal comminution or those with secondary loss of reduction should be treated surgically. $41,54,55$

\section{Surgical approaches \\ Volar approach}

Henry's volar approach is the most used approach for the treatment of DRFs. The classic approach makes use of a safe interval between brachioradialis and radial artery, and the modified approach between flexor carpi radialis tendon and radial artery to gain access to the fracture. ${ }^{56,57}$ Multiple modifications to this approach exist. It can be extended distally to allow the release of transverse carpal ligament for visualisation of complex intraarticular fractures. ${ }^{58}$

The choice of plate construct and plating technique should be individualised to the patient's profile, fracture pattern and surgeon's experience. ${ }^{59,60}$ Volar plate fixation is the commonly used treatment method among surgeons for displaced DRFs. ${ }^{10}$ Fixed-angle volar plates are designed to transfer load from the intact subchondral bone through metaphysis to the diaphysis. ${ }^{18}$ Locking plates have been reported to have improved fracture site stability against axial and bending forces over non-locked plates by biomechanics studies. ${ }^{61-63}$ However, their superiority over non-locked plates has not been demonstrated in practice. Clinical studies reporting on fixation of displaced articular fractures treated with locked plates have reported good results. ${ }^{64-66}$ Locked plates allow for polyaxial screw fixation and can address comminuted fragments through

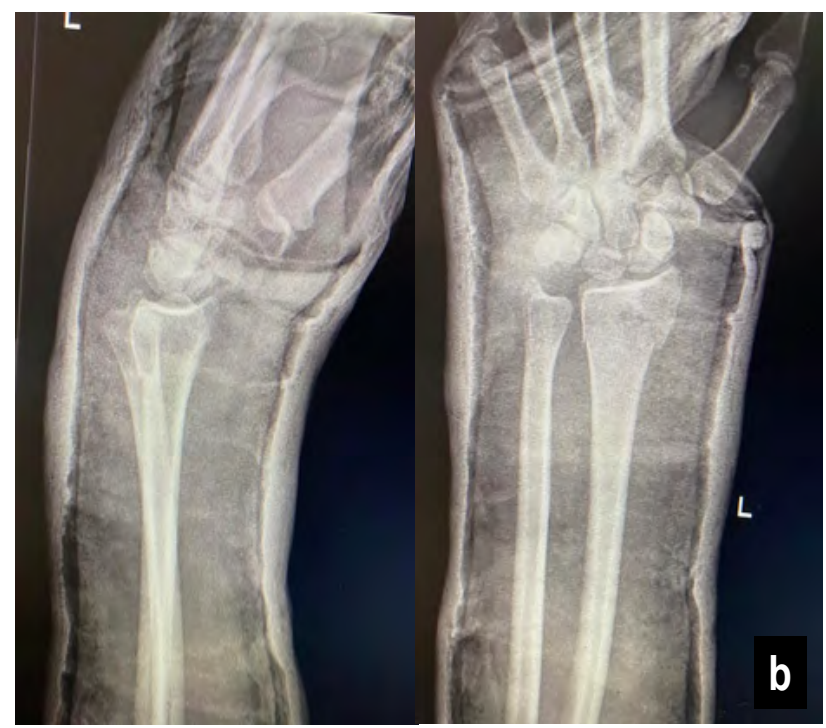

Figure 2. Plain X-ray images of a patient treated successfully with closed reduction and cast immobilisation. a) Anteroposterior (AP) and lateral view X-rays showing intra-articular distal radius fracture; b) Post-reduction X-rays with restored articular congruency, radial length and volar inclination 
multi-hole design. ${ }^{18}$ The choice of bicortical locked screws has not demonstrated superiority over unicortical screws. ${ }^{67,68}$ Similarly, plates with multiple distal screw holes have not been shown to provide superior fracture stability over those with single-row locked screw holes. ${ }^{69}$ The use of screws has been reported to have better torsional and compressive stability over pegs by the biomechanical studies. . $^{55} 70$

Plate failure and other complications following volar plating are not uncommon. Wilson et al. reported $17 \%$ complication rates in patients (mean age 56.5 years) treated with volar-locking plate, at 17.5 weeks mean follow-up. Loss of fracture reduction and CTS were the two commonly reported complications. ${ }^{71}$ Johnson et al. reported similar complications in their cohort of 204 patients with a mean age of 55 years. However, the complication rate following volar plating was lower $(9.7 \%) .^{72}$ Flexor tendon rupture is not uncommon following volar plating. Flexor pollicis longus (FPL) is the most commonly ruptured tendon ( $57 \%$ of cases), followed by flexor digitorum profundus (FDP) to the index finger. ${ }^{73}$ Extensor tendon irritation and rupture is not uncommon, following volar plate fixation of DRFs, and it has been associated with long dorsal penetrating screws, among other factors. ${ }^{71,74,75}$

\section{Dorsal approach}

The dorsal approach to DRFs provides intra-articular visualisation and direct assessment of articular reduction. It is generally used in patients with severe metaphyseal dorsal comminution and those with dorsally angulated intra-articular fractures. ${ }^{76,77}$ Historically, dorsal plating has been associated with high complications and risk of extensor tendons rupture. ${ }^{41,76,77}$ Modern plate designs have been shown to reduce the risk of dorsal tendon attrition. Spiteri et al. reported no tendon ruptures in 46 patients treated with modern-design low-profile dorsal plates and 17 treated with combined volar and dorsal plates at the five-year follow-up. However, $8.7 \%$ had reported extensor tendons irritation, and the plates were removed in all of them. ${ }^{78}$

\section{External fixation}

External fixation is a viable option for complex intra-articular DRFs and open fractures. It is commonly indicated for temporary fracture stabilisation. ${ }^{79}$ Bajwa et al. reported a significantly worse mean DASH score of 12.2 in patients treated with external fixator for intra-articular DRFs compared to a mean DASH score of 3.5 in those treated with ORIF. ${ }^{80}$ Similarly, Roh et al. reported comparable functional outcomes between external fixation and volar plate fixation in a prospective randomised trial of 92 patients with a minimum 12-month follow-up. The external fixator group had higher complication rates of $29 \%$ compared to $17 \%$ in the ORIF group. ${ }^{81}$

\section{Intramedullary fixation}

Intramedullary fixation for DRFs has been reported with enthusiasm as an option for treatment of DRFs. Tan et al. reported superior immediate- and intermediate-term functional outcomes in patients treated with intramedullary nails for DRFs compared to those treated in a cast. ${ }^{82}$ Similarly, Çalbiyik and Ipek reported good results in a cohort of 68 young adults, with a mean age of 46 years treated with an intramedullary fixation for extra-articular and simple intra-articular DRFs. ${ }^{83}$

\section{Arthroplasty}

Arthroplasty procedure for wrist fracture is a fairly new phenomenon and evidence is limited to small sample size studies. Vergnenègre et al. reported good functional outcomes in eight elderly patients treated with Sofia wrist hemiarthroplasty system (Biotech) for unreconstructable intra-articular fractures. ${ }^{84}$

\section{Arthroscopic-assisted surgery}

Arthroscopic-assisted surgery for DRFs has been used as an adjunct to DRFs since the 1980s. However, it has failed to gain popularity because it is time-consuming and technically demanding, with increased risk of compartment syndrome. ${ }^{85}$ Fluoroscopy has been the modality of choice for evaluation of articular stepoff. However, multiple studies have shown that arthroscopy is superior to fluoroscopy in evaluation of the articular surface. ${ }^{86-88}$ Adjunct wrist arthroscopy is indicated in patients with radial styloid fractures, die-punch fractures, articular step-off of $>2 \mathrm{~mm}$, flipped osteochondral fragment, central comminution as well as three- to four-part fractures. ${ }^{89}$

\section{Regional and local anaesthesia}

The wide awake local anaesthesia no tourniquet (WALANT) technique in the management of wrist and hand conditions has been a topic of interest in recent literature. Prior literature could not demonstrate the benefits of WALANT in patients' wrist fractures. ${ }^{90}$ However, recent literature has demonstrated WALANT to be tolerable during fixation of DRFs without a tourniquet, with a faster recovery period and similar functional outcomes to general anaesthesia, and it is more cost-effective. ${ }^{91,92}$

\section{Adjuncts to surgery}

\section{Bone graft}

A Cochrane database analysis of randomised trials concluded that there was insufficient evidence on functional outcomes and safety of the use of grafts in DRFs. ${ }^{93}$ That said, in elderly patients with comminuted fractures and metaphyseal bone loss following restoration of length and alignment, bone graft substitutes are sometimes necessary. Although no graft is superior, the iliac crest bone graft can be used in cases of major bone loss, and fracture non-union is recommended. ${ }^{94}$ Pedestal bone loss can be managed with bone graft in closed fractures, and staged bone graft reconstruction should be considered in patients with open fractures. ${ }^{18,95}$

\section{Calcium phosphate cement}

Calcium phosphate use in DRFs has been reported to provide improved fracture stability in fractures treated with either external fixator or K-wire fixation in biomechanics studies. ${ }^{96-98}$ Zimmermann et al. reported good results and cement incorporation in 26 postmenopausal women managed with injectable calcium phosphate bone cement and K-wires for intra-articular DRFs with a metaphyseal void of at least $5 \mathrm{~mm}$. This was compared to those treated with cast immobilisation or K-wire fixation without the use of bone cement following the reduction. ${ }^{99}$ The indications for bone cement use are not clearly defined in the literature. Ozer and Chung concluded that indications and choice of graft substitute should be based on the needs of the individual patient until further comparative research clarifies the indications and most appropriate material for a given fracture and clinical situation. ${ }^{94}$

\section{Pronator quadratus repair}

Pronator quadratus repair following volar plating has not been shown to have a functional impact. ${ }^{100-102}$ Some studies suggest this repair may be protective against flexor tendons rupture. ${ }^{103}$

\section{Carpal tunnel release during fracture fixation}

Prophylactic carpal tunnel release (CTR) in patients with DRFs is not recommended. ${ }^{104,105}$ Acute CTR should be done in patients with persistent and progressive features of acute CTS. ${ }^{22,23,106,107}$ 
Delayed release of more than 36 hours has been associated with irreversible nerve damage, whereas patients released acutely regained full nerve function. ${ }^{108-110}$

\section{Postoperative care and rehabilitation}

Postoperative rehabilitation programmes remain controversial and centre-specific. ${ }^{111}$ Postoperative care includes immobilisation, analgesia and elevation. ${ }^{112}$ Postoperative immobilisation of two weeks versus six weeks after volar plate fixation has shown no difference in long-term range of motion or functional outcomes. Although earlier range of motion exercises speeds up recovery in the acute setting, it did not translate into improved ultimate outcomes. ${ }^{113}$

Duprat et al. illustrated that the stability of a locking volar plate enabled immediate mobilisation with similar complication rates, but resulted in improved short-term outcomes in all aspects. ${ }^{114}$ When treatment entails closed reduction and casting, immobilisation for four to six weeks is preferred, provided that evidence of healing can be confirmed. ${ }^{115}$ In the absence of comorbidities, like diabetes, fracture union will have taken place. If in doubt, radiographs can be used to confirm union.

The majority of function is regained by three months, provided that good alignment was achieved, but continuous improvements up to 12 months can be expected with a slow return of grip strength. ${ }^{113}$

Athletes need to be individualised. Contact athletes can return to sport once they have achieved a pain-free range of motion and completed sport-specific drills and practice. Sports where wrist function is not required needs to be discussed with the patient and practised at their own discretion while being well informed and made aware of the risks. ${ }^{113}$

\section{Adjuvant therapy}

\section{Vitamin C supplementation}

Empiric vitamin $\mathrm{C}$ for the prevention of complex regional pain syndrome (CRPS) remains controversial. Its use has been recommended since Zollinger proved some benefit in 1999, but recent randomised controlled trials failed to demonstrate such benefit. ${ }^{116-118}$

\section{Vitamin D supplementation}

Vitamin D deficiency is common in the elderly population with fragility DRFs. ${ }^{119,120}$ Several studies have demonstrated hypovitaminosis $D$ in young patients, even in the South African setting. ${ }^{121-123} \varnothing$ yen et al. found that the elderly who sustain DRFs had low vitamin $D$ levels compared to those who did not have fractures. ${ }^{119}$ However, Rozental et al. reported that, in Israel, there was no association of low vitamin D with DRFs. ${ }^{124}$ Amid contrasting evidence, we propose selective patient vitamin $\mathrm{D}$ testing and supplementation if diagnosed with hypovitaminosis D. Tladi proposed that one should use a regimen that contains high levels of vitamin D3. ${ }^{125}$

\section{Bisphosphonate therapy}

Timing to initiation of bisphosphonates did not alter union times or rates. Patients should be risk-stratified and initiated on bonesparing medication if indicated. ${ }^{126}$ Molvik and Khan reported significantly prolonged fracture union time in patients with DRFs treated with bisphosphonates in a systematic literature review. ${ }^{127}$ However, the clinical studies reported similar radiographic and functional outcomes between patients with acute DRFs treated with bisphosphonate therapy and those who were not given bisphosphonates. ${ }^{42,128,129}$

\section{Low-intensity ultrasound}

Low-intensity ultrasound showed promise by reducing fracture healing times from 98 days to 61 days in a study by Kristiansen et al., and from 40 days to 32 days in a study by Liu et al. No longterm benefit could be proven in these studies, and the cost over benefit of this modality remain a concern. ${ }^{130,131}$

\section{South African context}

Trauma is a huge burden on an already compromised public healthcare system in South Africa. The private sector treats about $16 \%$ of the general population while the government sector treats $84 \% .{ }^{132,133}$ Patients are waiting longer to receive elective surgery because of the limitation of theatres in state hospitals. ${ }^{134}$ The lack of resources results in delayed referrals of patients, compelling the treating surgeon to manage partially healed fractures that often result in long operating times and a high risk of complications. This ailing system has been further burdened by the Covid-19 pandemic. It is our opinion that surgeons should consider nonoperative treatment of selected DRFs. This could aid in relieving some of the pressure from the overburdened public health sector

\section{Conclusion}

Distal radius fractures are common among elderly females, with increasing prevalence among all age groups. Management of these injuries remains controversial with no clear guidelines and contrasting evidence in the literature. Although nonoperative treatment is still a viable option in most cases with good results, the recent trend has seen an increase in surgical treatment. Improvements in fixation plate design have shown promising results in the reduction of complications and restoration of function in those treated surgically. Osteoporosis treatment should be initiated early in at-risk populations. High-level evidence and treatment guideline protocols are still lacking on this subject.

\section{Learning points}

The incidence of DRFs in young adults is on the rise and they often follow high-energy mechanisms of injury.

Classification systems demonstrate a lack of reliability, and their role in guiding treatment is limited.

The majority of DRFs are amenable to conservative treatment but one should be wary of the risk of fracture collapse in high-risk populations, and time taken off work or sports in young patients.

DRFs are often the first sign of osteoporosis and clinicians should not miss this opportunity to treat these patients accordingly.

Surgical management is associated with higher financial costs.

\section{Ethics statement}

The authors declare that this submission is in accordance with the principles laid down by the Responsible Research Publication Position Statements as developed at the 2nd World Conference on research integrity in Singapore, 2010. Ethical approval for this study was not obtained - review article.

\section{Declaration}

The authors declare authorship of this article and that they have followed sound scientific research practice. This research is original and does not transgress plagiarism policies.

\section{Author contributions}

PR: Assembled the team of reviewers, co-ordinated the review process, conducted the primary review and compiled the manuscript

SK, MT, FD and GT: Conducted the primary review and assisted with writing and reviewing the written submission

SG: Reviewed the written submission and provided senior guidance 


\section{ORCID}

Rachuene PA https://orcid.org/0000-0003-4045-5301

Tladi MJ https://orcid.org/0000-0003-4997-3009

\section{References}

1. WHO. Zero draft proposal. Decade of healthy ageing. Available from: https://www.who.int ageing/decade-of-healthy-ageing. Accessed 17 June 2021

2. This is the average life expectancy in South Africa right now. Business Tech. Available from: https://businesstech.co.za/news/lifestyle/414781/this-is-the-average-life-expectancyin-south-africa-right-now/\#: : text=As $\% 20$ of $\% 20$ mid- $2020 \% 2 \mathrm{C} \% 20$ Stats, increasing $\% 20$ over\%20the\%20last\%20decade. Published 2020. Accessed 6 December 2020.

3. Levin LS, Rozell JC, Pulos N. Distal radius fractures in the elderly. J Am Acad Orthop Surg 2017;25(3):179-87. https://doi.org/10.5435/JAAOS-D-15-00676.

4. Mauck BM, Swigler CW. Evidence-based review of distal radius fractures. Orthop Clin North Am. 2018:49(2):211-22. https://doi.org/10.1016/j.ocl.2017.12.001.

5. Shauver MJ, Clapham PJ, Chung KC. An economic analysis of outcomes and complications of treating distal radius fractures in the elderly. J Hand Surg AM. 2011;36(12):1912-18.e3. https://doi.org/10.1016/j.jhsa.2011.09.039.

6. Macintyre NJ, Dewan N. Epidemiology of distal radius fractures and factors predicting risk and prognosis. J Hand Ther. 2016;29(2):136-45. https://doi.org/10.1016/j.jht.2016.03.003.

7. Rundgren J, Bojan A, Navarro CM, Enocson A. Epidemiology, classification, treatment and mortality of distal radius fractures in adults: an observational study of 23,394 fractures from the national Swedish fracture register. BMC Musculoskelet Disord. 2020;21(88):1-10. https:// doi.org/10.1186/s12891-020-3097-8

8. Gliatis JD, Plessas SJ, Davis TRC. Outcome of distal radial fractures in young adults. $J$ Hand Surg Br. 2000;25B(6):535-43. https://doi.org/10.1054/jhsb.2000.0373.

9. Porrino JA, Maloney $\mathrm{E}$, Scherer $\mathrm{K}$, et al. Fracture of the distal radius: Epidemiology and premanagement radiographic characterization. Am J Roent. 2014;203(3):551-59. https://doi. org/10.2214/AJR.13.12140

10. Sander AL, Leiblein M, Sommer $\mathrm{K}$, et al. Epidemiology and treatment of distal radius fractures: current concept based on fracture severity and not on age. Eur J Trauma Emerg Surg. 2020;46(3):585-90. https://doi.org/10.1007/s00068-018-1023-7.

11. Huetteman HE, Shauver MJ, Malay S, et al. Variation in the treatment of distal radius fractures in the United States: 2010 to 2015. Plast Reconstr Surg. 2019;143(1):159-67. https://doi.org/10.1097/PRS.0000000000005088.

12. Sander $\mathrm{AL}$, Leiblein $\mathrm{M}$, Sommer $\mathrm{K}$, et al. Epidemiology and treatment of distal radius fractures: current concept based on fracture severity and not on age. Eur J Trauma Emerg Surg. 2020;46(3):585-90. https://doi.org/10.1007/s00068-018-1023-7.

13. Shauver MJ, Yin H, Banerjee M, Chung KC. Current and future national costs to medicare for the treatment of distal radius fracture in the elderly. J Hand Surg Am. 2011;36(8):1282 87. https://doi.org/10.1016/j.jhsa.2011.05.017.

14. Colles A. On the fracture of the carpal extremity of the radius. N Engl J Med Surg 1814:3:368-72. https://doi.org/10.1056/NEJM181410010030410.

15. Augat $P$, Von Rüden $C$. Evolution of fracture treatment with bone plates. Injury. 2018;49(June):S2-S7. https://doi.org/10.1016/S0020-1383(18)30294-8.

16. Diaz-Garcia RJ, Chung KC. The evolution of distal radius fracture management: a historical treatise. Hand Clin. 2013;28(2):105-11. https://doi.org/10.1016/j.hcl.2012.02.007.

17. Rikli DA, Regazzoni P. Fractures of the distal end of the radius treated by internal fixation and early function a preliminary report of 20 cases. J Bone Jt Surg Br. 1996;78(4):588-92.

18. Rhee PC, Medoff RJ, Shin AY. Complex distal radius fractures: An anatomic algorithm for surgical management. J Am Acad Orthop Surg. 2017;25(2):77-88. https://doi.org/10.5435 JAAOS-D-15-00525.

19. Kobayashi M, Garcia-Elias M, Nagy L, et al. Axial loading induces rotation of the proxima carpal row bones around unique screw-displacement axes. J Biomech. 1997;30(11 12):1165-67. https://doi.org/10.1016/S0021-9290(97)00080-8.

20. Poppler LH, Moran SL. Acute distal radioulnar joint instability evaluation and treatment. Hand Clin. 2020;36(4):429-41. https://doi.org/10.1016/j.hcl.2020.07.005

21. Medoff RJ. Essential radiographic evaluation for distal radius fractures. Hand Clin 2005;21(3):279-88. https://doi.org/10.1016/j.hcl.2005.02.008.

22. Niver GE, llyas AM. Carpal tunnel syndrome after distal radius fracture. Orthop Clin North Am. 2012;43(4):521-27. https://doi.org/10.1016/j.ocl.2012.07.021.

23. Pope D, Tang P. Carpal tunnel syndrome and distal radius fractures. Orthop Clin North Am. 2018;34(1):27-32. https://doi.org/10.1016/j.hcl.2017.09.003

24. Walenkamp MMJ, Aydin S, Mulders MAM, et al. Predictors of unstable distal radius fractures: A systematic review and meta-analysis. J Hand Surg Eur Vol. 2016;41(5):501-15 https://doi.org/10.1177/1753193415604795

25. Chen L, Liu L, Woo J, et al. Sarcopenia in Asia: Consensus report of the Asian Working Group for Sarcopenia. J Am Med Dir Assoc. 2021;15(2):95-101. https://doi.org/10.1016/j. jamda.2013.11.025

26. Roh $\mathrm{YH}, \mathrm{Koh} \mathrm{Y}$ Do, Noh $\mathrm{JH}$, et al. Evaluation of sarcopenia in patients with distal radius fractures. Arch Osteoporos. 2017;12(1):1-7. https://doi.org/10.1007/s11657-016-0303-2.

27. Roh YH, Noh JH, Gong HS, Baek GH. Effect of low appendicular lean mass, grip strength and gait speed on the functional outcome after surgery for distal radius fractures. Arch Osteoporos. 2017;12(1):41. https://doi.org/10.1007/s11657-017-0335-2.
28. Meena S, Sharma P, Sambharia AK, Dawar A. Fractures of distal radius: an overview. J Fam Med Prim Care. 2014;3(4):325-32. https://doi.org/10.4103/2249-4863.148101.

29. Harness NG, Ring DC, Zurakowski D, Jupiter J. The influence of three-dimensional computed tomography reconstructions on the characterization and treatment of distal radial fractures. J Bone Jt Surg. 2006;88(6):1315-23. https://doi.org/10.2106/JBJS.E.00686.

30. Pruitt DL, Gilula LA, Manske PR, Vannier MW. Computed tomography scanning with image reconstruction in evaluation of distal radius fractures. J Hand Surg. 1994;19(5):720-27. https://doi.org/10.1016/0363-5023(94)90174-0.

31. Bregni $M$, Cahueque $M$, Cobar $A$. Historical perspective of distal radius fracture classifications in the twentieth century. J Clin Exp Orthop. 2016;2(26). https://doi. org/10.4172/2471-8416.100026

32. Kural C, Sungur I, Kaya I, et al. Evaluation of the reliability of classification systems used for distal radius fractures. Orthopedics. 2010;33(11):11-15. https://doi. org/10.3928/01477447-20100924-14.

33. Handoll HH, Madhok R. Closed reduction methods for treating distal radial fractures in adults. Cochrane Database Syst Rev. 2003;(1):CD003763. https://doi. org/10.1002/14651858.CD003763

34. Ipaktchi K, Livermore M, Lyons C, Banegas R. Current concepts in the treatment of distal radial fractures. Orthopedics. 2013:36(10):778-84. https://doi. org/10.3928/01477447-20130920-07

35. Belloti JC, Gomes Dos Santos JB, Erazo JP, et al. A new method for classifying distal radius fracture: The IDEAL classification. Rev Bras Ortop. 2013;48(1):36-40. https://doi. org/10.1016/j.rboe.2012.06.002

36. Azi ML, Teixeira MB, De Carvalho SF, et al. Computed tomography vs standard radiograph in preoperative planning of distal radius fractures with articular involvement. Strateg Trauma Limb Reconstr. 2019;14(1):15-19. https://doi.org/10.5005/jp-journals-10080-1420.

37. Van Buijtenen JM, Van Tunen MLC, Zuidema WP, et al. Inter- and intra-observer agreement of the AO classification for operatively treated distal radius fractures. Strateg Trauma Limb Reconstr. 2015;10(3):155-59. https://doi.org/10.1007/s11751-015-0237-z.

38. Kleinlugtenbelt YV, Groen SR, Ham SJ, et al. Classification systems for distal radius fractures: Does the reliability improve using additional computed tomography? Acta Orthop. 2017;88(6):681-87. https://doi.org/10.1080/17453674.2017.1338066.

39. Mansur H, Gripp LD. Evaluation of three classification systems for fractures of the distal end of the radius: Frykman, Universal and A.O. Rev Bras Cir Plástica - Brazilian J Plast Sugery. 2020;35(2):198-202. https://doi.org/10.5935/2177-1235.2020rbcp0033.

40. Kodama $\mathrm{N}$, Takemura $\mathrm{Y}$, Ueba $\mathrm{H}$, et al. Acceptable parameters for alignment of distal radius fracture with conservative treatment in elderly patients. J Orthop Sci. 2014;19(2):292-97. https://doi.org/10.1007/s00776-013-0514-y.

41. Obert L, Rey PB, Uhring J, et al. Fixation of distal radius fractures in adults: A review. Orthop Traumatol Surg Res. 2013;99(2):216-34. https://doi.org/10.1016/j.otsr.2012.03.023.

42. Ostergaard PJ, Hall MJ, Rozental TD. Considerations in the treatment of osteoporotic distal radius fractures in elderly patients. Curr Rev Musculoskelet Med. 2019;12(1):50-56. https:// doi.org/10.1007/s12178-019-09531-z.

43. Lafontaine M, Hardy D, Delince P. Stability assessment of distal radius fractures. Injury. 1989;20:208-10. https://doi.org/10.1016/0020-1383(89)90113-7.

44. Mackenney PJ, McQueen MM, Elton R. Prediction of instability in distal radial fractures. J Bone Jt Surg. 2006;88(9):1944-51. https://doi.org/10.2106/JBJS.D.02520.

45. Walenkamp MMJ, Aydin S, Mulders MAM, et al. Predictors of unstable distal radius fractures: A systematic review and meta-analysis. J Hand Surg. 2016;41(5):501-15. https:/l doi.org/10.1177/1753193415604795.

46. Diaz-Garcia RJ, Oda T, Shauver MM, Chung KC. A systematic review of outcomes and complications of treating unstable distal radius fractures in the elderly. J Hand Surg. 2011;36(5):824-35.e2. https://doi.org/10.1016/j.jhsa.2011.02.005.

47. Earnshaw SA, Aladin A, Surendran S, Moran CG. Closed reduction of Colles fractures: Comparison of manual manipulation and finger-trap traction - A prospective, randomized study. J Bone Jt Surg. 2002;84(3):354-58. https://doi. org/10.2106/00004623-200203000-00004

48. Lichtman DM, Bindra RR, Boyer $M$, et al. Treatment of distal radius fractures. J Am Acad Orthop Surg. 2010;18:180-89. https://doi.org/10.1007/978-3-642-34746-7_91.

49. Dailey SK, Miller AR, Kakazu R, et al. The effectiveness of mini-c-arm fluoroscopy for the closed reduction of distal radius fractures in adults: a randomized controlled trial. J Hand Surg AM. 2018;43(10):927-31. https://doi.org/10.1016/j.jhsa.2018.02.015.

50. Hassellund SS, Williksen $\mathrm{JH}$, Laane MM, et al. Cast immobilization is non-inferior to volar locking plates in relation to QuickDASH after one year in patients aged 65 years and older: a randomized controlled trial of displaced distal radius fractures. Bone Joint J. 2021;103B(2):247-55. https://doi.org/10.1302/0301-620X.103B2.BJJ-2020-0192.R2.

51. Venkatesh RB, Maranna GK, Narayanappa RKB. A comparative study between closed reduction and cast application versus percutaneous K-wire fixation for extraarticular fracture distal end of radius. J Clin Diagnostic Res. 2016;10(2):RC05-RC09. https://doi.org/10.7860/ JCDR/2016/18266.7220.

52. Costa ML, Achten J, Parsons NR, et al. Percutaneous fixation with Kirschner wires versus volar locking plate fixation in adults with dorsally displaced fracture of distal radius: Randomised controlled trial. BMJ. 2014;349(August):1-10. https://doi.org/10.1136/bmj. g4807.

53. Costa ML, Achten J, Rangan A, et al. Percutaneous fixation with Kirschner wires versus volar locking-plate fixation in adults with dorsally displaced fracture of distal radius: five-yea 
follow-up of a randomized controlled trial. Bone Joint J. 2019;101-B(8):978-83. https://doi. org/10.1302/0301-620X.101B8.BJJ-2018-1285.R1.

54. Fournier MN, Cline JT, Seal A, et al. Operative distal radial fractures: A comparison of time to surgery after evaluation by surgical and nonsurgical providers in a walk-in clinic. Orthop Clin NA. 2020;51(2):235-39. https://doi.org/10.1016/j.ocl.2019.11.006.

55. Walenkamp MMJ, Bentohami A, Beerekamp MSH, et al. Functional outcome in patients with unstable distal radius fractures, volar locking plate versus external fixation: A meta-analysis. Strateg Trauma Limb Reconstr. 2013;8(2):67-75. https://doi.org/10.1007/s11751-013-0169-4.

56. Protopsaltis TS, Ruch DS. Volar approach to distal radius fractures. J Hand Surg. 2008;33(6):958-65. https://doi.org/10.1016/j.jhsa.2008.04.018.

57. Alluri RK, Hill JR, Ghiassi A. Distal radius fractures: Approaches, indications, and techniques. J Hand Surg Am. 2016;41(8):845-54. https://doi.org/10.1016/j.jhsa.2016.05.015.

58. Gwathmey FW, Brunton LM, Pensy RA, Chhabra AB. Volar plate osteosynthesis of dista radius fractures with concurrent prophylactic carpal tunnel release using a hybrid flexor carp radialis approach. J Hand Surg. 2010;35(7):4-6. https://doi.org/10.1016/j.jhsa.2010.03.043.

59. Marshall T, Momaya A, Eberhardt A, et al. Biomechanical comparison of volar fixed-angle locking plates for AO C3 distal radius fractures: Titanium versus stainless steel with compression. J Hand Surg Am. 2015;40(10):2032-38. https://doi.org/10.1016/j. jhsa.2015.06.098

60. Disseldorp DJG, Hannemann PFW, Poeze M, Brink PRG. Dorsal or volar plate fixation of the distal radius: does the complication rate help us to choose? J Wrist Surg. 2016;5(3):202-10. https://doi.org/10.1055/s-0036-1571842.

61. Levin SM, Nelson CO, Botts JD, et al. Biomechanical evaluation of volar locking plates for distal radius fractures. Hand. 2008;3(1):55-60. https://doi.org/10.1007/s11552-007-9063-1.

62. Liporace FA, Kubiak EN, Jeong GK, lesaka K. A biomechanical comparison of two volar locked plates in a dorsally unstable distal radius fracture model. J Trauma. 2006;61(3):66872. https://doi.org/10.1097/01.ta.0000234727.51894.7d.

63. Willis AA, Kutsumi K, Zobitz ME, Cooney III WP. Internal fixation of dorsally displaced fractures of the distal part of the radius. A biomechanical analysis of volar plate fracture stability. J Bone Jt Surg. 2006;88-A(11):2411-17. https://doi.org/10.2106/JBJS.E.00946

64. Orbay JL, Fernandez DL. Volar fixation for dorsally displaced fractures of the dista radius: A preliminary report. J Hand Surg. 2002;27A(2):205-15. https://doi.org/10.1053/ jhsu.2002.32081.

65. Drobetz $\mathrm{H}$, Kutscha-lissberg $\mathrm{E}$. Osteosynthesis of distal radial fractures with a volar locking screw plate system. Int Orthop. 2003;27:1-6. https://doi.org/10.1007/s00264-002-0393-x.

66. Martinez-mendez D, Lizaur-utrilla A. Prospective study of comminuted articular distal radius fractures stabilized by volar plating in the elderly. Int Orthop. 2018;42:2243-48. https://doi. org/10.1007/s00264-018-3903-1.

67. Protais MAM, Miquel OHA, Binder AC. Systematic use of short unicortical epiphyseal locking screws versus full - length unicortical locking screws in distal radius fracture volar plating: A prospective and comparative study. Eur J Orthop Surg Traumatol. 2021. Online ahead of print. https://doi.org/10.1007/s00590-021-02899-0.

68. Oh G, Kim H, Lee J II. Engineering biomechanical evaluation of the stability of extraarticular distal radius fractures fixed with volar locking plates according to the length of the distal locking screw. Comput Methods Biomech Biomed Engin. 2020;24(8):922-32. https:// doi.org/10.1080/10255842.2020.1861254.

69. Ramavath A, Howard N, Lipscombe S. Biomechanical considerations for strategies to improve outcomes following volar plating of distal radius fractures. J Orthop. 2019;16(5):44550. https://doi.org/10.1016/j.jor.2019.04.006.

70. Iba K, Ozasa Y, Wada T, et al. Efficacy of radial styloid targeting screws in volar plate fixation of intra-articular distal radial fractures: a biomechanical study in a cadaver fracture model. $J$ Orthop Surg Res. 2010;5(90):1-8. https://doi.org/10.1186/1749-799X-5-90.

71. Wilson J, Viner JJ, Johal KS, Woodruff MJ. Volar locking plate fixations for displaced distal radius fractures: An evaluation of complications and radiographic outcomes. Hand. 2018;13(4):466-72. https://doi.org/10.1177/1558944717717505.

72. Johnson NA, Cutler L, Dias JJ, et al. Complications after volar locking plate fixation of distal radius fractures. Injury. 2014;45(3):528-33. https://doi.org/10.1016/j.injury.2013.10.003.

73. Asadollahi S, Keith PPA. Flexor tendon injuries following plate fixation of distal radius fractures: A systematic review of the literature. J Orthopaed Traumatol. 2013;14(4):227-34 https://doi.org/10.1007/s10195-013-0245-z.

74. Thorninger R, Madsen ML, Wæver $\mathrm{D}$, et al. Complications of volar locking plating of distal radius fractures in 576 patients with 3.2 years follow-up. Injury. 2017;48(6):1104-9. https:// doi.org/10.1016/j.injury.2017.03.008.

75. Tarallo L, Mugnai R, Zambianchi F, et al. Volar plate fixation for the treatment of distal radius fractures: Analysis of adverse events. J Orthop Trauma. 2013;27(12):740-45. https://doi. org/10.1097/BOT.0b013e3182913fc5.

76. Lutsky K, Boyer M, Goldfarb C. Dorsal locked plate fixation of distal radius fractures. J Hand Surg. 2013;38(7):1414-22. https://doi.org/10.1016/j.jhsa.2013.04.019.

77. Wei J, Yang TB, Luo W, et al. Complications following dorsal versus volar plate fixation of distal radius fracture: A meta-analysis. J Int Med Res. 2013;41(2):265-75. https://doi. org/10.1177/0300060513476438.

78. Spiteri $\mathrm{M}, \mathrm{Ng} \mathrm{W}$, Matthews $\mathrm{J}$, et al. Three year review of dorsal plating for complex intra-articular fractures of the distal radius. J Hand Surg Asian Pac Vol. 2018;23(2):221-26. https://doi.org/10.1142/S2424835518500248.

79. Wei DH, Poolman RW, Bhandari M, et al. External fixation versus internal fixation for unstable distal radius fractures: A systematic review and meta-analysis of comparative clinical trials. J Orthop Trauma. 2012;26(7):386-94. https://doi.org/10.1097/ BOT.0b013e318225f63c.

80. Bajwa AS, Rammappa M, Lee L, Nanda R. Treatment of unstable distal radius fractures: non-invasive dynamic external fixator versus volar locking plate - functional and radiological outcome in a prospective case-controlled series. SICOT J. 2015;1:34. https://doi. org/10.1051/sicotj/2015033.

81. Roh YH, Lee BK, Baek JR, et al. A randomized comparison of volar plate and external fixation for intra-articular distal radius fractures. J Hand Surg Am. 2015;40(1):34-41. https:/l doi.org/10.1016/j.jhsa.2014.09.025.

82. Tan V, Bratchenko W, Nourbakhsh A, Capo J. Comparative analysis of intramedullary nail fixation versus casting for treatment of distal radius fractures. J Hand Surg. 2012;37(3):46068.e1. https://doi.org/10.1016/j.jhsa.2011.10.041.

83. Çalbiyik M, Ipek $D$. Use of different methods of intramedullary nailing for fixation of distal radius fractures: A retrospective analysis of clinical and radiological outcomes. Med Sc Monit. 2018;24:377-86. https://doi.org/10.12659/MSM.907885.

84. Vergnenègre $\mathrm{G}$, Hardy $\mathrm{J}$, Mabit $\mathrm{C}$, et al. Hemiarthroplasty for complex distal radius fractures in elderly patients. J Wrist Surg. 2015;04(03):169-73. https://doi. org/10.1055/s-0035-1558840.

85. Ogawa T, Tanaka T, Yanai T, et al. Analysis of soft tissue injuries associated with distal radius fractures. BMC Sports Sci Med Rehabil. 2013;5(19):1-4.

86. Abe $Y$, Yoshida $K$, Tominaga $Y$. Less invasive surgery with wrist arthroscopy for distal radius fracture. J Orthop Sci. 2013;18(3):398-404. https://doi.org/10.1007/s00776-013-0371-8.

87. Augé WK, Velázquez PA. The application of indirect reduction techniques in the dista radius: The role of adjuvant arthroscopy. Arthroscopy. 2000;16(8):830-35. https://doi. org/10.1053/jars.2000.17717

88. Ono $\mathrm{H}$, Furuta $\mathrm{K}$, Fujitani $\mathrm{R}$, et al. Distal radius fracture arthroscopic intraarticular displacement measurement after open reduction and internal fi xation from a volar approach. J Orthop Sci. 2010;15:502-8. https://doi.org/10.1007/s00776-010-1484-y.

89. Shkolnikova J, Harvey J. Wrist arthroscopy in the management of distal radius fractures. Ann Jt. 2018;3(77):1-13. https://doi.org/10.21037/aoj.2018.08.06.

90. Hopkins PM. Does regional anaesthesia improve outcome? $\mathrm{Br} \mathrm{J}$ Anaesth. 2015;115(S2):ii26-ii33. https://doi.org/10.1093/bja/aev377.

91. Lu C-K, Liu W-C, Lu I-C, et al. Is wide-awake local anesthesia no tourniquet technique in distal radius plating surgery a comfortable procedure? A prospective case-control study. Res Square; 2020. 2020:1-14. https://doi.org/10.21203/rs.3.rs-44922/v1.

92. Tahir M, Zaffar Z, Anwar K, et al. Is wide-awake local anesthesia no tourniquet technique in distal radius plating surgery a comfortable procedure? a prospective case-control study. Res Square; 2020. 2020;9(7):1-14. https://doi.org/10.21203/rs.3.rs-44922/v1.

93. Handoll HHG, Watts AC. Bone grafts and bone substitutes for treating distal radial fractures in adults. Cochrane Database Syst Rev. 2008;(2):CD006836. https://doi. org/10.1002/14651858.CD006836.pub2.

94. Ozer K, Chung KC. The use of bone grafts and substitutes in the treatment of distal radius fractures. Hand Clin. 2012:28(2):217-23. https://doi.org/10.1016/j.hcl.2012.02.004.

95. Medoff RJ, Shin AY. Complex distal radius fractures: an anatomic algorithm for surgical management. J Am Acad Orthop Surg. 2017;25(2):77-88. https://doi.org/10.5435/ JAAOS-D-15-00525.

96. Higgins TF, Dodds SD, Wolfe SW. A biomechanical analysis of fixation of intra-articular distal radial fractures with calcium-phosphate bone cement. J Bone Jt Surg. 2002;84(9):1579-86. https://doi.org/10.2106/00004623-200209000-00010.

97. Ladd AL, Pliam NB. Use of bone-graft substitutes in distal radius fractures. J Am Acad Orthop Surg. 1999;7(5):279-90. https://doi.org/10.5435/00124635-199909000-00001.

98. Larsson S, Bauer TW. Use of injectable calcium phosphate cement for fracture fixation: a review. Clin Orthop Relat Res. 2002;(395):23-32.

99. Zimmermann R, Gabl M, Lutz M, et al. Injectable calcium phosphate bone cement Norian SRS for the treatment of intra-articular compression fractures of the distal radius in osteoporotic women. Arch Orthop Trauma Surg. 2003;123(1):22-27. https://doi.org/10.1007/ s00402-002-0458-8.

100. Hinds RM, Montero-lopez N, Brock K, et al. Assessment of pronator quadratus repair integrity using dynamic ultrasonography following volar plate fixation for distal radius fractures. Hand. 2020;15(I):111-15. https://doi.org/10.1177/1558944718787327.

101. Hershman SH, Immerman I, Bechtel C, et al. The effects of pronator quadratus repair on outcomes after volar plating of distal radius fractures. J Orthop Trauma. 2013;27(3):130-33. https://doi.org/10.1097/BOT.0b013e3182539333.

102. Häberle S, Sandmann GH, Deiler S, et al. Pronator quadratus repair after volar plating of distal radius fractures or not? Results of a prospective randomized trial. Eur J Med Res. 2015;20(1):1-8. https://doi.org/10.1186/s40001-015-0187-4.

103. Huang HK, Wang JP, Chang MC. Repair of pronator quadratus with partial muscle split and distal transfer for volar plating of distal radius fractures. J Hand Surg Am. 2017;42(11):935. e1-935.e5. https://doi.org/10.1016/j.jhsa.2017.08.018.

104. Al-Amin Z, Senyürek SA, Van Lieshout EMM, Wijffels MME. Systematic review and pooled analysis of the rate of carpal tunnel syndrome after prophylactic carpal tunnel release in patients with a distal radius fracture. Hand Surg Rehabil. 2018;37(3):155-59. https://doi. org/10.1016/j.hansur.2018.02.004

105. Earp BE, Mora AN, Floyd WE, Blazar PE. Predictors of acute carpal tunnel syndrome following ORIF of distal radius fractures: A matched case-control study. J Hand Surg Glob Online. 2019;1(1):6-9. https://doi.org/10.1016/j.jhsg.2018.10.002 
106. Floyd WE, Earp BE, Blazar PE. Acute median nerve problems in the setting of a distal radius fracture. J Hand Surg Am. 2015;40(8):1669-71. https://doi.org/10.1016/j.jhsa.2015.04.005.

107. Odumala O, Ayekoloye C, Packer G. Prophylactic carpal tunnel decompression during buttress plating of the distal radius - Is it justified? Injury. 2001;32(7):577-79. https://doi. org/10.1016/S0020-1383(00)00198-4.

108. Ford J, Ali MS. Acute carpal tunnel syndrome. J Bone Jt Surg. 1986;68-B(5):758-59.

109. Schnetzler KA. Acute carpal tunnel syndrome. J Am Acad Orthop Surg. 2008;16:276-82. https://doi.org/10.5435/00124635-200805000-00006.

110. Bauman TD, Gelberman RH, Mubarak SJ, Garfin SR. The acute carpa tunnel syndrome. Clin Orthop Relat Res. 1981;156:151-56. https://doi. org/10.1097/00003086-198105000-00019.

111. Koval K, Haidukewych GJ, Service B, Zirgibel BJ. Controversies in the management of distal radius fractures. J Am Acad Orthop Surg. 2014;22(9):566-75. https://doi.org/10.5435/ JAAOS-22-09-566.

112. Krischak GD, Krasteva A, Schneider $F$, et al. Physiotherapy after volar plating of wrist fractures is effective using a home exercise program. Arch Phys Med Rehabil. 2009;90(4):537-44. https://doi.org/10.1016/j.apmr.2008.09.575.

113. Beleckas C, Calfee R. Distal radius fractures in the athlete. Curr Rev Musculoskelet Med. 2017;10(1):62-71. https://doi.org/10.1007/s12178-017-9385-8.

114. Duprat A, Diaz J, Vernet $P$, et al. Volar locking plate fixation of distal radius fractures: Splint versus immediate mobilization. J Wrist Surg. 2018:07(03):237-42. https://doi. org/10.1055/s-0037-1620271.

115. Ikpeze TC, Smith HC, Lee DJ, Elfar JC. Distal radius fracture outcomes and rehabilitation. Geriatr Orthop Surg Rehabil. 2016;7(4):202-5. https://doi.org/10.1177/2151458516669202.

116. Ekrol I, Duckworth AD, Ralston SH, et al. The influence of vitamin $C$ on the outcome of distal radial fractures: A double-blind, randomized controlled trial. J Bone Jt Surg. 2014;96(17):1451-59. https://doi.org/10.2106/JBJS.M.00268.

117. Özkan S, Teunis T, Ring DC, Chen NC. What is the effect of vitamin $C$ on finger stiffness after distal radius fracture? A double-blind, placebo-controlled randomized trial. Clin Orthop Relat Res. 2019;477(10):2278-86. https://doi.org/10.1097/CORR.0000000000000807.

118. Zollinger PE, Tuinebreijer W, Kreis R, Breederveld RS. Effect of vitamin C on frequency of reflex sympathetic dystrophy in wrist fractures: A randomised trial. Lancet. 2000;354(9195):2025-28. https://doi.org/10.1016/S0140-6736(99)03059-7.

119. Øyen J, Apalset EM, Gjesdal CG, et al. Vitamin D inadequacy is associated with low-energy distal radius fractures: A case-control study. Bone. 2011;48:1140-45. https://doi. org/10.1016/j.bone.2011.01.021.

120. Jang WY, Chung MS, Baek GH, et al. Vitamin D levels in post-menopausal Korean women with a distal radius fracture. Injury. 2012;43(2):237-41. https://doi.org/10.1016/j. injury.2011.10.020.

121. Lisenda L, Simmons D, Firth GB, et al. Vitamin D status in blount disease. J Paediatr Orthop. 2016;36(5):e59-e62. https://doi.org/10.1097/BP0.0000000000000607.

122. Poopedi MA, Norris SA, Pettifor JM. Factors influencing the vitamin D status of 10 -year-old urban South African children. Public Health Nutr. 2010;14(2):334-39. https://doi.org/10.1017/ S136898001000234X.

123. Rachuene PA, Ide Villiers S, Dey R, et al. Combined South African Orthopaedic Congress. In: Retrospective audit of serum vitamin D levels and plain X-ray outcomes in patients who underwent latarjet procedure for shoulder instability. Durban; 2019.

124. Rozental TD, Herder LM, Walley KC, et al. 25-Hydroxyvitamin-D and bone turnover marker levels in patients with distal radial fracture. J Bone Jt Surg Am. 2015;97(20):1685-93. https:// doi.org/10.2106/JBJS.0.00313.

125. Tladi MJ. Do we need to investigate for vitamin $D$ levels in patients going for correction? Foot Ankle Orthop. 2018;(November):3-4

126. Xue D, Li F, Chen G, et al. Do bisphosphonates affect bone healing? A meta-analysis of randomized controlled trials. J Orthop Surg Res. 2014;9(1). https://doi. org/10.1186/1749-799X-9-45.

127. Molvik $\mathrm{H}$, Khan $\mathrm{W}$. Bisphosphonates and their influence on fracture healing: a systematic review. Osteoporos Int. 2015;26(4):1251-60. https://doi.org/10.1007/s00198-014-3007-8.

128. Rozental TD, Vazquez MA, Chacko AT, et al. Comparison of radiographic fracture healing in the distal radius for patients on and off bisphosphonate therapy. J Hand Surg Am. 2009;34(4):595-602. https://doi.org/10.1016/j.jhsa.2008.12.011.

129. Shoji KE, Earp BE, Rozental TD. The effect of bisphosphonates on the clinical and radiographic outcomes of distal radius fractures in women. J Hand Surg Am. 2018:43(2):115-22. https://doi.org/10.1016/j.jhsa.2017.09.006.

130. Liu $Y$, Wei $X$, Kuang $Y$, et al. Ultrasound treatment for accelerating fracture healing of the distal radius. A control study 1. Acta Cir Bras. 2014;29(11):765-70. https://doi.org/10.1590/ S0102-86502014001800012.

131. Kristiansen TK, Ryaby JP, Mcabe J, et al. Accelerated healing of distal radial fractures with the use of specific, low-intensity ultrasound. A multicenter, prospective, randomized, doubleblind, placebo-controlled study. J Bone Jt Surg. 1997;79(7):961-73.

132. Naidoo S. The South African National Health Insurance: A revolution in health-care delivery! J Public Health. 2012;34(1):149-50. https://doi.org/10.1093/pubmed/fds008.

133. Tladi MJ, Kumbirai PT, Mariba MT, Tladi SM. Analysis of road traffic accident claimants evaluated for medico-legal assessment, Pretoria, South Africa. Int J Clin Med Cases. 2019;2(1):1-5. https://doi.org/10.31021/ijcmc.20192116.

134. Ngcelwane M. New frontiers in the battle against the burden of musculoskeletal trauma from motor vehicle accidents. SA Ortho J. 2018;17(2):9-10 